\title{
Molecular Characteristics of Methicillin-Resistant Staphylococcus epidermidis on the Abdominal Skin of Females before Laparotomy
}

\author{
Pin-Jia Wang ${ }^{1,2}$, Cheng-Bin Xie ${ }^{3}$, Feng-Hui Sun ${ }^{2}$, Li-Juan Guo ${ }^{2}$, Min Dai ${ }^{2}, \mathrm{Xi} \mathrm{Cheng}^{2}$ and \\ Yong-Xin Ma ${ }^{1, *}$ \\ 1 Medical Genetics, West China Shool of Medicine, West China Hospital, Sichuan University, Chengdu 610041, \\ China; pinjiawong@foxmail.com \\ 2 School of Medical Laboratory Science, Chengdu Medical College, Chengdu 610500, China; \\ sunfenghui_83@hotmail.com (F.-H.S.); gljemily@163.com (L.-J.G.); daimin1015@163.com (M.D.); \\ cissi7@foxmail.com (X.C.) \\ 3 Department of Laboratory Medicine, Sichuan Provincial Hospital for Women and Children, \\ Chengdu 610045, China; chengbinxie@foxmail.com \\ * Correspondence: mayongxin@gmail.com; Tel.: +86-28-8516-4008
}

Academic Editor: Chris Jackson

Received: 1 April 2016; Accepted: 20 June 2016; Published: 22 June 2016

\begin{abstract}
Staphylococcus epidermidis, especially methicillin-resistant strains, may be the source of surgical site infections and may be a reservoir of staphylococcal cassette chromosome mec (SCCmec) for $S$. aureus. The aim of this study was to investigate the prevalence of methicillin-resistant S. epidermidis (MRSE) on the abdominal skin of females before laparotomy and determine the molecular characteristics and antimicrobial susceptibility patterns of these isolates. MRSE was found in 54 of 157 isolates based on mecA gene detection, and there was no difference in icaA gene carriage rate between MRSE and methicillin-susceptible S. epidermidis (MSSE) isolates. Antimicrobial susceptibility profiles were determined by broth microdilution antimicrobial susceptibility testing according to the latest CLSI manuals. All MRSE isolates had unfavorable antimicrobial susceptibility patterns. Twenty-three MRSE strains (42.6\%) were multi-drug resistant. SCCmec typing and pulsed field gel electrophoresis (PFGE) typing was performed. Thirty-nine (72.2\%) had a single SCCmec type, whereas $1.9 \%$ had two types. Fourteen strains (25.9\%) were non-typeable (NT). The most frequent MRSE genotype was SCCmec type IVa. High diversity with PFGE patterns was obtained for MRSE, and there were no isolates exhibiting identical pulsotype. The results confirm that methicillin-resistant strains are frequently present among $S$. epidermidis on the abdominal skin of females before laparotomy. Moreover, resistance profiles seem to have no association with the SCCmec types or PFGE types for most common antibiotics.
\end{abstract}

Keywords: methicillin-resistant Staphylococcus epidermidis; SCCmec; PFGE; skin; laparotomy; antibiotic resistant

\section{Introduction}

Surgical interventions are common in the day-to-day practice of obstetrics and gynecology, and surgical site infections (SSIs) are frequent complications of abdominal gynecological operations. Surveys of postoperative wound infections in obstetrics and gynecology departments showed that the overall wound infection rate was $5.87 \%$ to $12.6 \%$ [1-3]. Postoperative wound infections can increase the costs and hospital stay. Moreover, they lead to higher morbidity and lower life quality of surgical patients. The widespread use of antibiotic prophylaxis has reduced but not eradicated the prevalence of serious postoperative infections. 
For most gynecological SSIs, the source of pathogens is the endogenous flora of the patient's skin or vagina [4]. When the skin or vagina is incised, the exposed tissues are at risk for contamination with endogenous flora. S. epidermidis is the most prevalent and persistent species found on the human skin and mucous membranes, constituting $65 \%$ to $90 \%$ of all staphylococci isolated from these environments [5], and it may act as a source of later bacteremia and surgical site infections. The majority of cases reported identified S. epidermidis as a common bacterium responsible for wound infections after surgery [6-8]. In one study by Martens et al. [9], 64\% infected wounds after cesarean delivery had positive bacterial cultures, with S. epidermidis (29\%) being the most frequent isolates.

In recent decades, S. epidermidis has emerged as the cause of hospital-acquired infections. Virulence is mainly attributed to biofilm formation based on polysaccharide intercellular adhesin (PIA), which is encoded by S. epidermidis icaADBC operon genes. About $75 \%-90 \%$ of S. epidermidis strains circulating in hospitals have been estimated to be methicillin-resistant $[10,11]$. The methicillin-resistance to $S$. epidermidis is usually due to the mecA gene, which is carried by staphylococcal cassette chromosome mec (SCCmec) and produces a special penicillin binding protein 2a (PBP2a) with low affinity for $\beta$-lactams. SCCmec can also carry genetic elements for other antibiotic resistance; therefore, most of the methicillin-resistant strains (MRSE) are also highly resistant to other antibiotics. In diverse collections of $S$. epidermidis isolates, molecular characterization of this element revealed five SCCmec types previously found in S. aureus [12]. Additionally, there were high numbers of new and non-typeable SCCmec types [13-16]. These results indicate a high degree of genetic diversity within the SCCmec elements carried by S. epidermidis. Therefore, it is imperative that the genetic diversity of MRSE isolates should be determined by using a gold standard genotyping technique, such as pulsed field gel electrophoresis (PFGE).

Several studies have described the antimicrobial susceptibility of bacteria isolated from SSIs and prevalence of staphylococcal strains in the surgical site, but antimicrobial susceptibility and molecular characteristics of MRSE on the abdominal skin of females before laparotomy are extremely limited, which fails to guide infection control for gynecological SSIs. Therefore, the aim of this study was to investigate the prevalence of MRSE on the abdominal skin of females before laparotomy and determine the molecular characteristics and antimicrobial resistance patterns of these isolates.

\section{Results}

\subsection{SCCmec Typing of MRSE}

A total of 157 S. epidermidis isolates were found on the abdominal skin of 160 females (98.1\%). Fifty-four isolates were positive for mec $A$ and were thus classified as MRSE (34.4\%), 13 isolates were positive for $i c a A(8.28 \%)$, and no difference was observed in $i c a A$ positive rates between MRSE and methicillin-susceptible S. epidermidis (MSSE) isolates (respectively 5 and $8, p>0.05$ ). Among MRSE isolates, established SCCmec types were detected in 40 isolates $(74.1 \%)$, with $1.9 \%$ cassettes of type I, $1.9 \%$ cassettes of type II $+\mathrm{IVb}, 7.4 \%$ cassettes of type III, $51.9 \%$ cassettes of type IVa, $5.6 \%$ cassettes of type IVd, and $5.6 \%$ cassettes of type V. The remaining 14 isolates $(25.9 \%)$ carried non-typeable (NT) cassettes. SCCmec type IV (including IVa and IVd) $(n=31)$ was predominant among the MRSE isolates from abdominal skin of females, followed by NT $(n=14), \mathrm{III}(n=4), \mathrm{V}(n=3)$, and I and II+IVb $(n=1$ each).

\subsection{Antimicrobial Susceptibility of MRSE}

All of the 54 MRSE isolates were susceptible to some non- $\beta$-lactam antibiotics, such as rifampicin, gatifloxacin, moxifloxacin, quinupristin-dalfopristin, linezolid, and vancomycin. The majority of the MRSE isolates were resistant to many common antibiotics, such as penicillin, ampicillin, erythromycin, azithromycin, and trimethoprim-sulfamethoxazole. Resistance rates of the MSSE isolates were significantly less than those of the MRSE isolates to ciprofloxacin, levofloxacin, gentamicin, erythromycin, azithromycin, and trimethoprim-sulfamethoxazole $(p<0.05)$. The results indicated that 
most of the non- $\beta$-lactam antibiotic resistances were correlated with the mec $A$ gene, just as $\beta$-lactam antibiotics. Resistance rates for the remaining antibiotics in the MSSE and MRSE isolates are shown in Table 1 . We found that the susceptibility to oxacillin was variable in MRSE with minimal inhibitory concentrations (MICs) ranging from 0.25 to $4 \mu \mathrm{g} / \mathrm{mL}$. Carriages of mec $A$ in these isolates were not always associated with significant resistance to oxacillin. Five of the mecA positive S. epidermidis showed oxacillin sensitivity.

Table 1. Resistance profiles of 54 methicillin-resistant S. epidermidis (MRSE) isolates and 103 methicillin-susceptible S. epidermidis (MSSE) isolates.

\begin{tabular}{cccccccc}
\hline & \multicolumn{3}{c}{ MSSE $(\boldsymbol{n = 1 0 3 )}$} & \multicolumn{3}{c}{ MRSE ( $\boldsymbol{n = 5 4 )}$} & MIC \\
\cline { 2 - 6 } Antibiotics & \%R(n) & MIC50 & MIC90 & \%R(n) & MIC50 & MIC90 & Range \\
\hline Penicillin G & $85.4(88)$ & 16 & 16 & $96.3(52)$ & 16 & 16 & $0.03-16$ \\
Ampicillin & $84.5(87)$ & 16 & 16 & $96.3(52)$ & 16 & 16 & $0.25-16$ \\
Oxacillin & $0(0)$ & 0.25 & 0.25 & $90.7(49)$ & 4 & 4 & $0.25-4$ \\
Gentamicin & $4.9(5)$ & 4 & 4 & $14.8(8)$ & 4 & 16 & $4-16$ \\
Rifampin & $0(0)$ & 1 & 1 & $0(0)$ & 1 & 1 & $1-1$ \\
Ciprofloxacin & $3.9(4)$ & 1 & 1 & $29.6(16)$ & 1 & 4 & $1-4$ \\
Gatifloxacin & $0(0)$ & 2 & 2 & $0(0)$ & 2 & 2 & $2-2$ \\
Levofloxacin & $2.9(3)$ & 2 & 2 & $31.5(17)$ & 2 & 8 & $2-8$ \\
Moxifloxacin & $0(0)$ & 2 & 2 & $0(0)$ & 2 & 2 & $2-2$ \\
Clindamycin & $25.2(26)$ & 2 & 4 & $59.3(32)$ & 4 & 4 & $2-4$ \\
Azithromycin & $12.6(13)$ & 0.5 & 2 & $14.8(8)$ & 0.5 & 4 & $0.5-4$ \\
Erythromycin & $38.8(40)$ & 2 & 8 & $64.8(35)$ & 8 & 8 & $2-8$ \\
Linezolid & $47.6(49)$ & 0.5 & 8 & $68.5(37)$ & 8 & 8 & $0.5-8$ \\
Vancomycin & $0(0)$ & 2 & 2 & $0(0)$ & 2 & 2 & $2-4$ \\
Chimethoprim /Sulfamethoxazole & $0(0)$ & 2 & 2 & $0(0)$ & 2 & 4 & $2-16$ \\
Quinupristin/Dalfopristin & $7.8(8)$ & 8 & 8 & $11.1(6)$ & 8 & 32 & $8-32$ \\
Tetracycline & $0(0)$ & 1 & 1 & $0(0)$ & 1 & 1 & $1-1$ \\
\hline
\end{tabular}

S. epidermidis carrying SCCmec type I, type II + IVb, type III, type V, and type NT cassettes were all resistant to penicillin and ampicillin, whereas each of type IVa and type IVd was susceptible. Except for those $\beta$-lactam antibiotics, SCCmec type IVa and type NT MRSE isolates had almost identical resistance rates to gentamicin, ciprofloxacin, levofloxacin, azithromycin, erythromycin, chloramphenicol, tetracycline, and trimethoprim-sulfamethoxazole $(p>0.05)$. The results indicate that resistance profiles seem to have no association with the SCCmec types for most common antibiotics. However, more notably, the resistance rate to clindamycin of the SCCmec type IVa was significantly lower than that of the SCCmec type NT MRSE isolates $(p<0.01)$. The details of the resistance rates among MRSE with different SCCmec types are summarized in Table 2.

Thirty different resistance patterns were obtained for all the MRSE isolates, and twenty-three isolates $(42.6 \%)$ were multi-drug resistant. However, only 17 resistance patterns for the MSSE isolates and 10 isolates $(9.7 \%)$ were multi-drug resistant. The resistance patterns were quite different in between, but detailed data are not shown here. SCCmec types and PFGE types associated with these resistance patterns are shown in Table 3. There are seven isolates only resistant to oxacillin, erythromycin, and trimethoprim-sulfamethoxazole. Patterns with ERY resistance, OXA + CLI resistance, OXA + SXT resistance, OXA + SXT + ERY resistance, and OXA + GEN + CIP + SXT + ERY resistance appear more frequently in SCCmec type IVa isolates. Resistance patterns seem to have no relationship with the PFGE types. 
Table 2. Resistance profiles of 54 MRSE isolates with different staphylococcal cassette chromosome mec (SCCmec) types.

\begin{tabular}{cccccccc}
\hline Antibiotics & \multicolumn{7}{c}{ Resistant Isolates of SCCmec Type [\% (n)] } \\
\cline { 2 - 7 } & I $(\boldsymbol{n = 1 )}$ & $\begin{array}{c}\text { II + IVb } \\
(\boldsymbol{n}=\mathbf{1})\end{array}$ & $\begin{array}{c}\text { III } \\
(\boldsymbol{n}=\mathbf{4})\end{array}$ & $\begin{array}{c}\text { Iva } \\
(\boldsymbol{n}=\mathbf{2 8})\end{array}$ & $\begin{array}{c}\text { IVd } \\
(\boldsymbol{n}=\mathbf{3})\end{array}$ & $\mathbf{V}(\boldsymbol{n}=\mathbf{3})$ & $\begin{array}{c}\text { NT } \\
(\boldsymbol{n}=\mathbf{1 4})\end{array}$ \\
\hline Penicillin G & $100(1)$ & $100(1)$ & $100(4)$ & $96.4(27)$ & $66.7(2)$ & $100(3)$ & $100(14)$ \\
Ampicillin & $100(1)$ & $100(1)$ & $100(4)$ & $96.4(27)$ & $66.7(2)$ & $100(3)$ & $100(14)$ \\
Oxacillin & $100(1)$ & $100(1)$ & $75(3)$ & $89.3(25)$ & $66.7(2)$ & $100(3)$ & $100(14)$ \\
Gentamicin & $100(1)$ & $0(0)$ & $0(0)$ & $10.7(3)$ & $33.3(1)$ & $0(0)$ & $21.4(3)$ \\
Rifampin & $0(0)$ & $0(0)$ & $0(0)$ & $0(0)$ & $0(0)$ & $0(0)$ & $0(0)$ \\
Ciprofloxacin & $0(0)$ & $100(1)$ & $50(2)$ & $21.4(6)$ & $0(0)$ & $66.7(2)$ & $35.7(5)$ \\
Gatifloxacin & $0(0)$ & $0(0)$ & $0(0)$ & $0(0)$ & $0(0)$ & $0(0)$ & $0(0)$ \\
Levofloxacin & $0(0)$ & $100(1)$ & $50.0(2)$ & $25.0(7)$ & $0(0)$ & $66.7(2)$ & $35.7(5)$ \\
Moxifloxacin & $0(0)$ & $0(0)$ & $0(0)$ & $0(0)$ & $0(0)$ & $0(0)$ & $0(0)$ \\
Clindamycin & $0(0)$ & $100(1)$ & $25(1)$ & $67.9(19)$ & $66.7(2)$ & $100(3)$ & $42.9(6)$ \\
Azithromycin & $0(0)$ & $0(0)$ & $25(1)$ & $7.1(2)$ & $0(0)$ & $0(0)$ & $35.7(5)$ \\
Erythromycin & $100(1)$ & $100(1)$ & $25(1)$ & $60.7(17)$ & $66.7(2)$ & $66.7(2)$ & $78.6(11)$ \\
Linezolid & $100(1)$ & $100(1)$ & $25(1)$ & $67.9(19)$ & $66.7(2)$ & $66.7(2)$ & $78.6(11)$ \\
Vancomycin & $0(0)$ & $0(0)$ & $0(0)$ & $0(0)$ & $0(0)$ & $0(0)$ & $0(0)$ \\
Chloramphenicol & $0(0)$ & $0(0)$ & $0(0)$ & $0(0)$ & $0(0)$ & $0(0)$ & $0(0)$ \\
Quinupristin/Dalfopristin & $0(0)$ & $0(0)$ & $0(0)$ & $7.1(2)$ & $0(0)$ & $0(0)$ & $28.6(4)$ \\
Tetracycline & $0(0)$ & $0(0)$ & $0(0)$ & $0(0)$ & $0(0)$ & $0(0)$ & $0(0)$ \\
& $0(0)$ & $100(1)$ & $25(1)$ & $7.1(2)$ & $0(0)$ & $0(0)$ & $7.1(1)$ \\
\hline
\end{tabular}

Table 3. Resistance patterns of MRSE isolates.

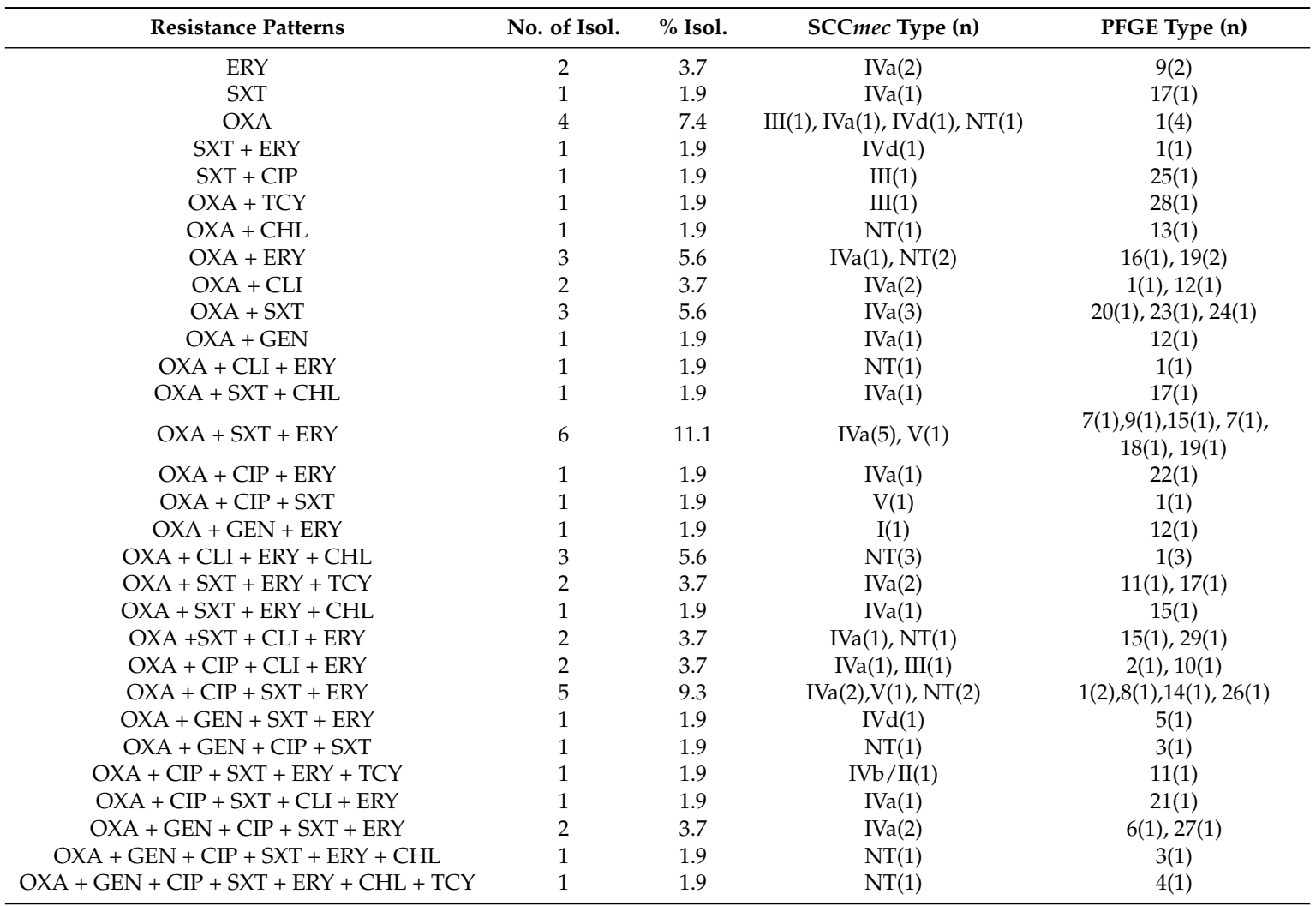

ERY: erythromycin; SXT: sulfamethoxazole; OXA: oxacillin; CIP: ciprofloxacin; TCY: tetracycline; CHL: chloramphenicol; CLI: clindamycin; GEN: gentamicin. 


\subsection{PFGE of MRSE}

PFGE for MRSE was performed and analyzed with a Dice similarity index of $79 \%$, and 54 MRSE isolates were clustered in 29 PFGE types (PT). There were no isolates with identical pulsotype, and the results showed a notable genetic diversity among the isolates (Figure 1). There were 21 PFGE types consisting of only a single SmaI pattern. The remaining PFGE types groups consisted of 2 to 13 SmaI-PFGE patterns. The most frequent PFGE types were pulsotype PT1 $(n=13)$, followed by types PT17 $(n=4), 9,12,15$, and 19 ( $n=3$ respectively). Except for PT1, 11, 12, and 19 isolates, most of the PFGE types consisted of one SCCmec cassettes. A relatively high similarity of pulsotype was found in the predominant SCCmec type IVa. Four isolates with SCCmec IVa were grouped in PT1 with a similarity of $79.09 \%$, and four isolates were grouped in PT17 with similarity of $82.67 \%$. Three isolates with SCCmec IVa were grouped in PT9 with a similarity of $83.22 \%$, and three isolates were grouped in PT15 with a similarity of $86.76 \%$. Two isolates with SCCmec IVa were grouped in PT12 with a similarity of $86.21 \%$, and two were grouped in PT19 with a similarity of $93.66 \%$.

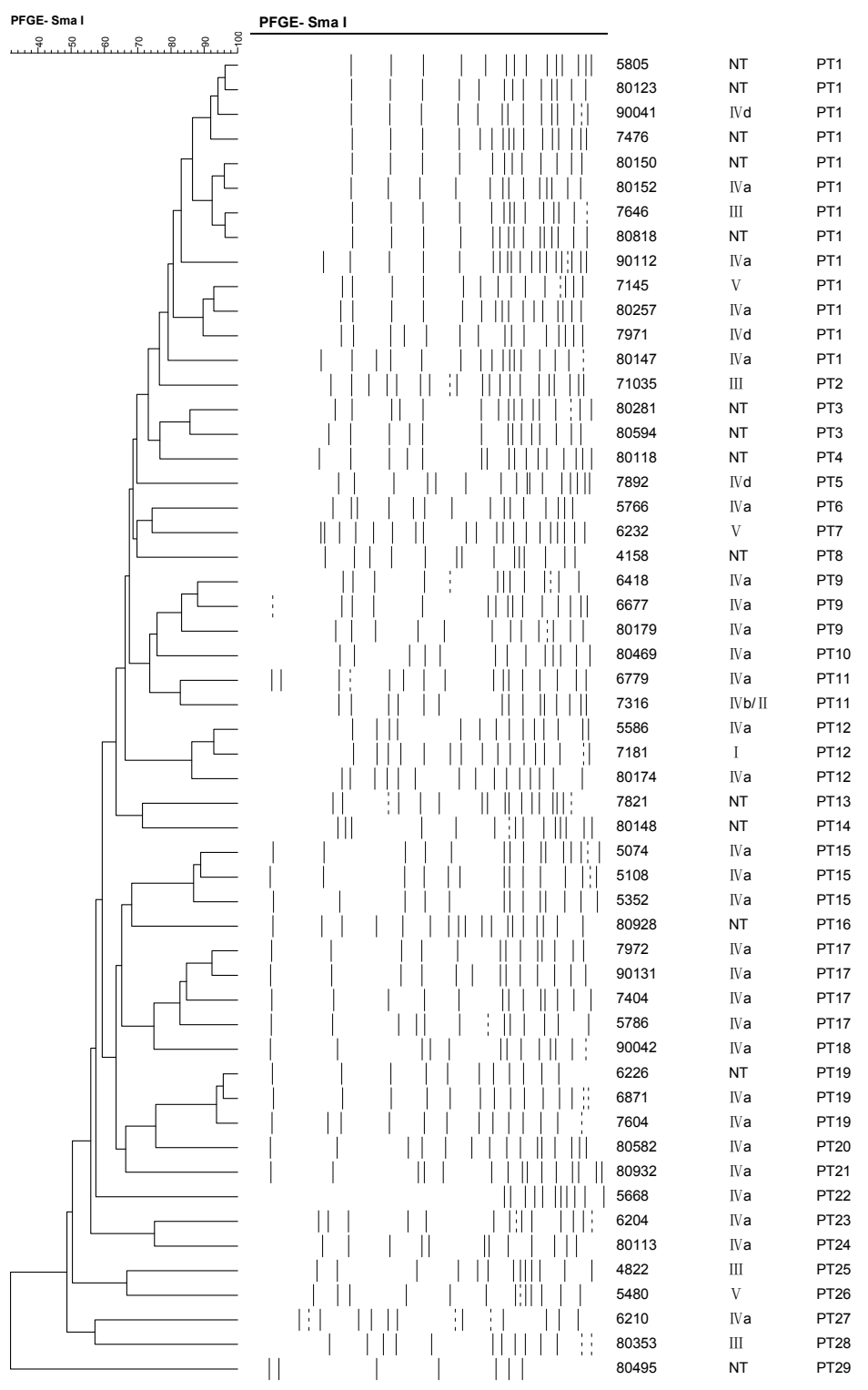

Figure 1. Dendrogram of pulsed-field gel electrophoresis patterns of MRSE isolates. At a Dice similarity index of 79\%, 29 PFGE types were identified. The strain number, the SCCmec type, and the PFGE type are indicated at the right of the dendrogram. 


\section{Discussion}

The human body is the habitat of large and varied populations of bacteria that are at the same time both potentially dangerous and helpful to human health. In recent years, there has been a strong interest to fully characterize the bacteria strains associated with different parts of the body under different health conditions [17-19]. S. epidermidis is the most significant member of the coagulase negative staphylococci (CoNS) and part of normal skin flora, and it has a benign relationship with the host, but it has emerged as the cause of serious infections, such as surgical wound infections. From our previous investigation, S. epidermidis was frequently isolated from peritoneal fluid of females with pelvic inflammatory disease, such as abdominal pain, fever, and foul-smelling vaginal discharge. Our observations also matched those of Szumała's investigation; they found that S. epidermidis was one of the most common bacteria (34.1\%) [20]. Therefore, we believe that S. epidermidis might be significantly associated with pelvic inflammatory disease or postoperative intra-abdominal infections of females.

This prospective study included 160 females before laparotomy due to ectopic pregnancy, caesarean section, uterine tumors, or pelvic inflammatory disease, to which little attention had been paid in previous reports. In this study, the carriage rate of S. epidermidis on the abdominal skin of these females was as high as $98.1 \%(157 / 160)$, the positive rate for mecA of S. epidermidis was as high as $34.4 \%$ (54/157); however, the positive rate for $i c a A$ was as low as $8.28 \%(13 / 157)$. However, it is worth noting that there was no difference in $i c a A$ positive rates between MRSE and MSSE isolates (respectively 5 and $8, p>0.05$ ), which means that the icaA gene could not be associated with mec $A$ gene for these isolates. Some previous reports have identified that horizontal transfer of SCCmec elements occurs between S. aureus and methicillin-resistant coagulase-negative Staphylococci [16,21]. SCCmec elements are very common in S. epidermidis in this study, which may act as an available reservoir for S. aureus to develop methicillin resistance [22,23]. Thus, it is very important for medical staff to understand the resistance profiles and genotype of MRSE of females before laparotomy to guide infection control and the reasonable use of antibiotics.

The circulation of different SCCmec types of MRSE varies in the population, environment, and geographical locations. SCCmec types have been used to distinguish community-associated methicillin resistant Staphylococci (CA-MRS) from healthcare-associated methicillin-resistant Staphylococci (HA-MRS). MRSA bacteremia with SCCmec II/III isolates has occurred more among patients with serious comorbidities and prolonged hospitalization, while community onset, skin and soft tissue infection, and deep-seated infection best predicted SCCmec IV/V MRSA bacteremia [24]. SCCmec type IV was common in MR-CoNS. Data from Jamaluddin [25] confirmed that SCCmec IVa was found in most community-acquired MRSE. Other researchers reported that $36 \%$ of MRSE harbored SCCmec type IV, and type IV was common among a geographically dispersed collection of S. epidermidis isolates [26]. Epidemiological studies and molecular characterization of methicillin-resistant staphylococci from healthy Jordanian population showed the MR-CoNS carriage was $54.2 \%$ and these isolates were characterized by single, double, and un-typeable SCCmec elements, with S. epidermidis SCCmec type IVa predominating [27]. In agreement with previous reports, this study found that SCCmec types I and II were few, while type IV was relatively common. SCCmec type IVa was predominant among MRSE isolates from the abdominal skin of females. A report from Shitrit [28] confirmed that patients with SCCmec type IV had fewer previous hospitalizations, less antibiotic treatment, and fewer invasive procedures, as well as fewer comorbid conditions and a shorter length of stay compared with other SCCmec-type patients.

In this study, SCCmec types were determined for most of the isolates (40 of 54), and the remaining isolates $(25.9 \%)$ could not be amplified by this M-PCR. This rate was consistent with a previous report with the same M-PCR [28]. Several previous studies have demonstrated that there is a higher frequency of non-typeable and new SCCmec types among S. epidermidis or other coagulase-negative staphylococci. Therefore, a considerable proportion of MRSE isolates cannot be assigned by the currently available PCR-based methods [29], which means to us that a new SCCmec typing technique especially for S. epidermidis should be developed as soon as possible. In this study, there was one isolate with two 
SCCmec type II $+\mathrm{IVb}$, and it is likely that the two SCCmec elements actually constitute a composite rather than two independent units [29].

Pulsed-field gel electrophoresis has been considered the gold standard for the molecular typing of S. epidermidis for many years. Here, using a high-resolution PFGE method, a high degree of genetic diversity of MRSE isolates was found. We observed 29 pulsotypes for these MRSE isolates, and there were no isolates with an identical pulsotype, which showed a high diversity in genotype of MRSE isolates. The diversity in this study indicated that there were no immediate transmissions of any MRSE isolates among females in the same hospital and that the research data were relatively valid, reliable, and representative.

The MRSE isolates in this study had an unfavorable antimicrobial susceptibility patterns. Although they were completely sensitive to some non- $\beta$-lactam antibiotics, such as rifampicin, gatifloxacin, moxifloxacin, quinupristin-dalfopristin, linezolid, and vancomycin, more than $50 \%$ of SCCmec IVa MRSE strains were resistant to many common antibiotics in clinic, such as penicillin, ampicillin, oxacillin, trimethoprim-sulfamethoxazole, azithromycin, and erythromycin. Moreover, the isolates with SCCmec type IV (including IVa and IVb) in this study, which are usually identified as community-acquired strains, were resistant to many non- $\beta$-lactam antibiotics. By contrast, previous studies showed that SCCmec types IV are generally susceptible to non- $\beta$-lactam antibiotics [30]. The research data suggested that SCCmec type IV strains should acquire resistance to non- $\beta$-lactam antibiotics in order to accommodate hospital environments and excessive antibiotic exposure. Comparing SCCmec type IVa with SCCmec type NT isolates, we found that they had almost identical resistance rates to many non- $\beta$-lactam antibiotics, which suggested that resistance profiles seem to have no association with the SCCmec types for most of the common antibiotics for these isolates. It could also be, of course, that the numbers of different SCCmec type isolate are not big enough to show the difference between resistance profiles and SCCmec types. However, more notably, the resistance rate to clindamycin of SCCmec type IVa was significantly less than that of SCCmec type NT MRSE isolates.

As is known to all, inappropriate and broad-spectrum antibiotic therapy may not only disrupt the normal balance of bacteria of the human body, but also facilitate colonization by multi-drug resistant bacteria. The patients who were receiving an appropriate antibiotic treatment could not be colonized by MRS strains until they have been exposed to these strains, so MRSE strains may seriously threaten the patients, especially those who will receive surgery. The research data in this study suggested that all preoperative patients including pregnant females may be the potential and important reservoirs of MRSE in hospital and community. It is important for medical staff to select appropriate antibiotic prophylaxis and conduct effective disinfection for preoperative patients to prevent and control the infection and spread of MRSE.

Consequently, although this study was performed at a single-center level and only concentrated on preoperative female patients, which means that data collection may be restricted and incomplete for some reasons, and different conclusions may be reached in a multivariate analysis if we expanded the number of enrolled cases, the research data in this study was able to clearly reflect the resistant patterns and genotype of MRSE of females before laparotomy. This study can provide medical staff with a better understanding of molecular epidemiology of MRSE in this region, which is very essential and meaningful for them to detect, treat, control, and prevent surgical site infections caused by this organism timely and efficiently.

\section{Materials and Methods}

\subsection{Specimen Collection}

This was a prospective cross-sectional study involving abdominal skin specimen of females from the age of 19 to 58 without skin or soft tissue infections and who were at the obstetrical or gynecological department from January to September 2015 in Sichuan Provincial Hospital for Women and Children, Chengdu, Sichuan, China. Abdominal surgeries were performed on these females due to ectopic 
pregnancy, caesarean section, uterine tumors, or pelvic inflammatory disease. The females provided written informed consent to participating in this study. Tegumentary specimens were obtained from abdominal incisions or puncture sites with moistened (sterile saline) swabs, which were directly inoculated onto Columbia blood agar.

\subsection{Bacterial Isolation}

S. epidermidis were identified by conventional methods after incubation for $24 \sim 48 \mathrm{~h}$ at $35^{\circ} \mathrm{C}$. Preliminary screening was based on Gram staining, catalase, plasma coagulase, and glucolysis tests. Final confirmation of S. epidermidis was performed with the API 20 Staph kit (Biomerieux, Marcy-l'Étoile, France). A total of 157 S. epidermidis non-duplicate isolates were recovered from the abdominal skin in females before laparotomy. All strains were stored in glycerin-buffered saline at $-70{ }^{\circ} \mathrm{C}$ and were subcultured twice onto Columbia blood agar before testing.

\subsection{Detection of mecA, icaA Gene, and SCCmec Typing}

All S. epidermidis isolates were further tested to determine mecA, icaA, and SCCmec types using polymerase chain reaction (PCR) assays described by Zhang et al. [31]. This SCCmec PCR typing assay contained 9 pairs of primers including the unique and specific primers for SCCmec types and subtypes I, II, III, IVa, IVb, IVc, IVd, and V, and the primers for the mec $A$ gene. We used mec $A$ gene detection as the gold standard for confirming MRSE. The following reference strains were used: NCTC for SCCmec type I; N315 for SCCmec type II; 85/2080 for SCCmec type III; JCSC4744 for SCCmec type IV; and HS663 for SCCmec type V. The results were reported as type I-V, and those isolates that were not type I-V were deemed non-typeable (NT).

\subsection{Antimicrobial Susceptibility Testing}

Minimal inhibitory concentrations (MICs) of 18 antibiotics (penicillin, ampicillin, oxacillin, gentamicin, rifampicin, ciprofloxacin, gatifloxacin, levofloxacin, moxifloxacin, sulfamethoxazole, clindamycin, azithromycin, erythromycin, linezolid, vancomycin, chloramphenicol, quinupristin-dalfopristin, and tetracycline) were determined for MRSE isolates using the broth microdilution method as recommended by the Clinical and Laboratory Standards Institute (CLSI, Wayne, MI, USA) guidelines (M100-S25). Isolates were classified as multi-drug resistant (MDR) if they were resistant to $\geqslant 3$ non- $\beta$-lactam antibiotic classes [32].

\subsection{PFGE Typing}

The SmaI DNA restriction fragments were separated by PFGE according to McDougal et al. [33]. Restriction fragments were separated using a Bio-Rad CHEF Mapper apparatus (Bio-Rad Laboratories Inc., Hercules, CL, USA). PFGE profiles obtained were analyzed with BioNumerics software (Applied Maths Inc., Austin, TX, USA). Clustering was performed by using the Dice similarity coefficient and the unweighted pair group method with arithmetic means (UPGMA), with optimization and position tolerance settings of 0.8 and 1.3, respectively. According to the criteria established by Miragaia et al. [15], a cutoff similarity value of $79 \%$ was used to establish PFGE types. The types obtained by the PFGE method are represented by numbers.

\subsection{Quality Control}

Standard aseptic sample collection and processing measures were strictly adhered to. For phenotypic identification of S. epidermidis, S. epidermidis ATCC 12228, and S. aureus ATCC 25923 were used as control strains, respectively. For genotyping, S. aureus ATCC 25923 (mecA-negative) and ATCC 43300 (mecA-positive) were used. For icaA gene PCR amplifying, S. epidermidis ATCC 12228 and ATCC 35984 were used as negative and positive controls respectively. 


\section{Conclusions}

The results indicated that methicillin-resistant strains are frequently present among S. epidermidis on the abdominal skin of females before laparotomy. The MRSE isolates had an unfavorable antimicrobial susceptibility patterns and high genetic diversity, moreover resistance profiles seem to have no association with the SCCmec types or PFGE types for most common antibiotics.

Acknowledgments: This work was supported by grants from the Sichuan Health and Family Commission of Sichuan Province (contract no. 120493 \& 130246) and Sichuan Provincial Education Department (contract no. 16ZB0281 \& 16TD0027). We thank Jiatang Li and Xiao Sun for their technical assistance.

Author Contributions: Pin-Jia Wang, Cheng-Bin Xie, and Yong-Xin Ma conceived and designed the experiments; Cheng-Bin Xie, Feng-Hui Sun, and Li-Juan Guo performed the experiments; Pin-Jia Wang, Min Dai, and Xi Cheng analyzed the data; Pin-Jia Wang, Cheng-Bin Xie, and Feng-Hui Sun wrote the paper.

Conflicts of Interest: The authors declare no conflict of interest.

$\begin{array}{ll}\text { Abbreviations } \\ \text { MRSE } & \text { methicillin-resistant Staphylococcus epidermidis } \\ \text { MSSE } & \text { methicillin-susceptible Staphylococcus epidermidis } \\ \text { SCCmec } & \text { staphylococcal cassette chromosome mec } \\ \text { PFGE } & \text { pulsed field gel electrophoresis } \\ \text { NT } & \text { non-typeable } \\ \text { SSIs } & \text { surgical site infections } \\ \text { MICs } & \text { minimal inhibitory concentrations }\end{array}$

\section{References}

1. Suwal, A.; Shrivastava, V.R.; Giri, A. A prospective study of wound infections after laparotomy in obstetrics and gynaecology department. Nepal. Med. Coll. J. 2012, 14, 267-270. [PubMed]

2. Shrestha, S.; Shrestha, R.; Shrestha, B.; Dongol, A. Incidence and risk factors of surgical site infection following cesarean section at Dhulikhel Hospital. Kathmandu Univ. Med. J. 2014, 12, 113-116. [CrossRef]

3. Shahane, V.; Bhawal, S.; Lele, U. Surgical site infections: A one year prospective study in a tertiary care center. Int. J. Health Sci. 2012, 6, 79-84. [CrossRef]

4. Altemeier, W.A.; Culbertson, W.R.; Hummel, R.P. Surgical considerations of endogenous infections-Sources, types, and methods of control. Surg. Clin. N. Am. 1968, 48, 227-240. [PubMed]

5. Kleinschmidt, S.; Huygens, F.; Faoagali, J.; Rathnayake, I.U.; Hafner, L.M. Staphylococcus epidermidis as a cause of bacteremia. Future Microbiol. 2015, 10, 1859-1879. [CrossRef] [PubMed]

6. Miyazaki, S.; Kakutani, K.; Maeno, K.; Takada, T.; Yurube, T.; Kurosaka, M.; Nishida, K. Surgical debridement with retention of spinal instrumentation and long-term antimicrobial therapy for multidrug-resistant surgical site infections after spinal surgery: A case series. Int. Orthop. 2015. in press. [CrossRef] [PubMed]

7. Kim, J.H.; Ahn, D.K.; Kim, J.W.; Kim, G.W. Particular features of surgical site infection in posterior lumbar interbody fusion. Clin. Orthop. Surg. 2015, 7, 337-343. [CrossRef] [PubMed]

8. Abdul-Jabbar, A.; Berven, S.H.; Hu, S.S.; Chou, D.; Mummaneni, P.V.; Takemoto, S.; Ames, C.; Deviren, V.; Tay, B.; Weinstein, P.; et al. Surgical site infections in spine surgery: Identification of microbiologic and surgical characteristics in 239 cases. Spine (Phila Pa 1976) 2013, 38, E1425-E1431. [CrossRef] [PubMed]

9. Martens, M.G.; Kolrud, B.L.; Faro, S.; Maccato, M.; Hammill, H. Development of wound infection or separation after cesarean delivery. Prospective evaluation of 2,431 cases. J. Reprod. Med. 1995, 40, 171-175. [PubMed]

10. Diekema, D.J.; Pfaller, M.A.; Schmitz, F.J.; Smayevsky, J.; Bell, J.; Jones, R.N.; Beach, M. Survey of infections due to Staphylococcus species: Frequency of occurrence and antimicrobial susceptibility of isolates collected in the United States, Canada, Latin America, Europe, and the Western Pacific region for the SENTRY Antimicrobial Surveillance Program, 1997-1999. Clin. Infect. Dis. 2001, 32, S114-S132. [PubMed]

11. Wang, L.F.; Li, J.L.; Ma, W.H.; Li, J.Y. Drug resistance analysis of bacterial strains isolated from burn patients. Genet. Mol. Res. 2014, 13, 9727-9734. [CrossRef] [PubMed]

12. Turlej, A.; Hryniewicz, W.; Empel, J. Staphylococcal cassette chromosome mec (Sccmec) classification and typing methods: An overview. Pol. J. Microbiol. 2011, 60, 95-103. [PubMed] 
13. Miragaia, M.; Couto, I.; de Lencastre, H. Genetic diversity among methicillin-resistant Staphylococcus epidermidis (MRSE). Microb. Drug Resist. 2005, 11, 83-93. [CrossRef] [PubMed]

14. Hanssen, A.M.; Sollid, J.U. Multiple staphylococcal cassette chromosomes and allelic variants of cassette chromosome recombinases in Staphylococcus aureus and coagulase-negative staphylococci from Norway. Antimicrob. Agents Chemother. 2007, 51, 1671-1677. [CrossRef] [PubMed]

15. Miragaia, M.; Carriço, J.A.; Thomas, J.C.; Couto, I.; Enright, M.C.; de Lencastre, H. Comparison of molecular typing methods for characterization of Staphylococcus epidermidis: Proposal for clone definition. J. Clin. Microbiol. 2008, 46, 118-129. [CrossRef] [PubMed]

16. Ibrahem, S.; Salmenlinna, S.; Virolainen, A.; Kerttula, A.M.; Lyytikäinen, O.; Jägerroos, H.; Broas, M.; Vuopio-Varkila, J. Carriage of methicillin-resistant Staphylococci and their SCCmec types in a long-term-care facility. J. Clin. Microbiol. 2009, 47, 32-37. [CrossRef] [PubMed]

17. Urbaniak, C.; Cummins, J.; Brackstone, M.; Macklaim, J.M.; Gloor, G.B.; Baban, C.K.; Scott, L.; O’Hanlon, D.M.; Burton, J.P.; Francis, K.P.; et al. Bacteria microbiota of human breast tissue. Appl. Environ. Microbiol. 2014, 80, 3007-3014. [CrossRef] [PubMed]

18. Tomic-Canic, M.; Perez-Perez, G.I.; Blumenberg, M. Cutaneous microbiome studies in the times of affordable sequencing. J. Dermatol. Sci. 2014, 75, 82-87. [CrossRef] [PubMed]

19. Whiteside, S.A.; Razvi, H.; Dave, S.; Reid, G.; Burton, J.P. The microbiome of the urinary tract-A role beyond infection. Nat. Rev. Urol. 2015, 12, 81-90. [CrossRef] [PubMed]

20. Szumała-Kakol, A.; Szymanowski, K.; Owedyk, M.; Banaszewski, S.; Skrzypczak, J. Microbiological flora cultured from peritoneal fluid of women in reproductive age. Ginekol. Pol. 2000, 71, 1026-1030. [PubMed]

21. Hanssen, A.M.; Kjeldsen, G.; Sollid, J.U. Local variants of Staphylococcal cassette chromosome mec in sporadic methicillin-resistant staphylococcus aureus and methicillin-resistant coagulase-negative Staphylococci: Evidence of horizontal gene transfer? Antimicrob. Agents Chemother. 2004, 48, 285-296. [CrossRef] [PubMed]

22. Barbier, F.; Ruppé, E.; Hernandez, D.; Lebeaux, D.; Francois, P.; Felix, B.; Desprez, A.; Maiga, A.; Woerther, P.L.; Gaillard, K.; et al. Methicillin-resistant coagulase-negative staphylococci in the community: High homology of SCCmec IVa between staphylococcus epidermidis and major clones of methicillin-resistant staphylococcus aureus. J. Infect. Dis. 2010, 202, 270-281. [CrossRef] [PubMed]

23. Otto, M. Coagulase-negative staphylococci as reservoirs of genes facilitating MRSA infection: Staphylococcal commensal species such as staphylococcus epidermidis are being recognized as important sources of genes promoting MRSA colonization and virulence. Bioessays 2013, 35, 4-11. [CrossRef] [PubMed]

24. Wang, J.L.; Wang, J.T.; Chen, S.Y.; Chen, Y.C.; Chang, S.C. Distribution of staphylococcal cassette chromosome mec Types and correlation with comorbidity and infection type in patients with MRSA bacteremia. PLoS ONE 2010, 5, e9489. [CrossRef] [PubMed]

25. Jamaluddin, T.Z.; Kuwahara-Arai, K.; Hisata, K.; Terasawa, M.; Cui, L.; Baba, T.; Sotozono, C.; Kinoshita, S.; Ito, T.; Hiramatsu, K. Extreme genetic diversity of methicillin-resistant staphylococcus epidermidis strains disseminated among healthy Japanese children. J. Clin. Microbiol. 2008, 46, 3778-3783. [CrossRef] [PubMed]

26. Wisplinghoff, H.; Rosato, A.E.; Enright, M.C.; Noto, M.; Craig, W.; Archer, G.L. Related clones containing SCCmec type IV predominate among clinically significant Staphylococcus epidermidis isolates. Antimicrob. Agents Chemother. 2003, 47, 3574-3579. [CrossRef] [PubMed]

27. Al-Bakri, A.G.; Al-Hadithi, H.; Kasabri, V.; Othman, G.; Kriegeskorte, A.; Becker, K. The epidemiology and molecular characterization of methicillin-resistant staphylococci sampled from a healthy Jordanian population. Epidemiol. Infect. 2013, 141, 2384-2391. [CrossRef] [PubMed]

28. Shitrit, P.; Openhaim, M.; Reisfeld, S.; Paitan, Y.; Regev-Yochay, G.; Carmeli, Y.; Chowers, M. Characteristics of SCCmec IV and V Methicillin-Resistant Staphylococcus aureus (MRSA) in Israel. Isr. Med. Assoc. J. 2015, 17, 470-475. [PubMed]

29. Zong, Z.; Peng, C.; Lü, X. Diversity of SCCmec elements in methicillin-resistant coagulase-negative staphylococci clinical isolates. PLoS ONE 2011, 6, e20191. [CrossRef] [PubMed]

30. Bukharie, H.A. A review of community-acquired methicillin-resistant staphylococcus aureus for primary care physicians. J. Family Community Med. 2010, 17, 117-120. [CrossRef] [PubMed]

31. Zhang, K.; McClure, J.A.; Elsayed, S.; Louie, T.; Conly, J.M. Novel multiplex PCR assay for characterization and concomitant subtyping of staphylococcal cassette chromosome mec types I to V in methicillin-resistant Staphylococcus aureus. J. Clin. Microbiol. 2005, 43, 5026-5033. [CrossRef] [PubMed] 
32. Magiorakos, A.P.; Srinivasan, A.; Carey, R.B.; Carmeli, Y.; Falagas, M.E.; Giske, C.G.; Harbarth, S.; Hindler, J.F.; Kahlmeter, G.; Olsson-Liljequist, B.; et al. Multidrug-resistant, extensively drug-resistant and pandrug-resistant bacteria: An international expert proposal for interim standard definitions for acquired resistance. Clin. Microbiol. Infect. 2012, 18, 268-281. [CrossRef] [PubMed]

33. McDougal, L.K.; Steward, C.D.; Killgore, G.E.; Chaitram, J.M.; McAllister, S.K.; Tenover, F.C. Pulsed-field gel electrophoresis typing of oxacillin-resistant staphylococcus aureus isolates from the united states: Establishing a national database. J. Clin. Microbiol. 2003, 41, 5113-5120. [CrossRef] [PubMed]

(C) 2016 by the authors; licensee MDPI, Basel, Switzerland. This article is an open access article distributed under the terms and conditions of the Creative Commons Attribution (CC-BY) license (http:/ / creativecommons.org/licenses/by/4.0/). 